\title{
Indução de resistência sistêmica à antracnose em feijoeiro-comum pela raça delta avirulenta de Colletotrichum lindemuthianum
}

\author{
Ângela Diniz Campos ${ }^{(1)}$, Magdolna Maria Vozarí Hampe ${ }^{(2)}$, Alfredo Gui Ferreira( ${ }^{(3)}$, Irajá Ferreira Antunes ${ }^{(1)}$ \\ e Luis Antônio Suita de Castro(1)
}

\begin{abstract}
(1)Embrapa Clima Temperado, Caixa Postal 403, CEP 96001-970 Pelotas, RS. E-mail: angela@cpact.embrapa.br, iraja@cpact.embrapa.br, suita@cpact.embrapa.br (2)Universidade Federal do Rio Grande do Sul (UFRGS), Instituto de Ciências Básicas da Saúde, Departamento de Bioquímica, CEP 91501-970 Porto Alegre, RS. E-mail: hampe@orion.ufrgs.br ${ }^{(3)}$ UFRGS, Instituto de Biociências, Departamento de Botânica. E-mail: ferreira@unb.br
\end{abstract}

\begin{abstract}
Resumo - O objetivo deste trabalho foi avaliar o potencial da raça delta avirulenta do fungo Colletotrichum lindemuthianum, como protetora contra raças virulentas deste fungo e quanto à capacidade de induzir resistência sistêmica em feijoeiro-comum (Phaseolus vulgaris). Quatro cultivares de feijoeiro foram avaliadas quanto às alterações nas atividades de beta-1,3-glucanase e quitinase, em dois estádios de desenvolvimento (V2 e R6), três dias após a aplicação de suspensão de esporos de $C$. lindemuthianum raça delta avirulenta, em comparação com aplicações de água e ácido salicílico. As plantas foram, então, infectadas com o patótipo virulento 33/95 de $C$. lindemuthianum em suspensão e, depois de cinco dias, foram reavaliadas quanto à atividade das enzimas. Observaram-se acréscimos significativos nas atividades da beta-1,3-glucanase e quitinase, após inoculação do fungo indutivo, nas duas avaliações, nos dois estádios de desenvolvimento. As atividades da beta-1,3-glucanase e da quitinase variaram entre as cultivares e entre os estádios de desenvolvimento das plantas. A correlação entre o índice de severidade da doença e a atividade das enzimas foi altamente significativa. $\mathrm{O}$ uso de C. lindemuthianum raça delta avirulenta diminuiu a severidade da doença e pode ter potencial para controlar a antracnose do feijoeiro.
\end{abstract}

Termos para indexação: Phaseolus vulgaris, ácido salicílico, beta-1,3-glucanase, controle biológico, enzimas hidrolíticas, quitinase.

\section{Induction of systemic resistance to anthracnose in common bean by the avirulent delta race of Colletotrichum lindemuthianum}

\begin{abstract}
The objectives of this work were to evaluate the potential of the avirulent delta race of Colletotrichum lindemuthianum as a protector against virulent races of this fungus and induce systemic resistance to anthracnose in common bean (Phaseolus vulgaris). Four common bean cultivars were evaluated for changes in the activities of beta-1,3-glucanase and chitinase at two common bean developmental stages, V2 and R6, three days after the infection with delta race of $C$. lindemuthianum, in comparison with control applications of water and salicylic acid. The plants were then infected with a spore suspension of 33/95, a virulent $C$. lindemuthianum patotype and reevaluated five days later for the enzyme activities. Significant increases in the activities of both beta-1,3glucanase and chitinase were observed after inoculation of inductive fungus at the two evaluation periods, at both plant development stages. The activities of both beta-1,3-glucanase and chitinase varied among cultivars and among plant development stages. A significant correlation was observed between the disease severity and the enzyme activity. The avirulent delta race of $C$. lindemuthianum reduced the severity of anthracnose on common bean and may have the potential to control the disease.
\end{abstract}

Index terms: Phaseolus vulgaris, salicylic acid, beta-1,3-glucanase, biocontrol, hydrolytic enzymes, chitinase.

\section{Introdução}

Os agentes de biocontrole contra doenças fúngicas têm sido desenvolvidos, porque apresentam potencial diverso e sustentável para o controle de doenças e promovem maior segurança e redução do desenvolvimento da resistência dos patógenos a fungicidas (Alabouvette et al., 2006).
Embora vários produtos de biocontrole estejam disponíveis, ainda há demanda por novos (Montesinos, 2003; Djonovic et al., 2007), e o entendimento de seus mecanismos de proteção tem grande importância para subsidiar o seu uso.

Mecanismos baseados, principalmente, em competição por espaço e por nutrientes, micoparasitismo, antibiose e elicitação de defesas da planta contribuem, 
simultânea ou subsequentemente, para o biocontrole de microrganismos (Janisiewicz \& Korsten, 2002; Djonovic et al., 2007). O biocontrole, no entanto, é dificultado por numerosas interações entre plantas, patógenos, microambiente e agentes de biocontrole. Woo et al. (2006) descreveram a identificação de Trichoderma harzianum e Trichoderma atroviride com genes de avirulência (Avr) relacionados à indução de resistência de plantas. Esses autores demonstraram a capacidade de Trichoderma spp. de transferir a proteína heteróloga para a planta, durante a colonização da raiz. Eles usaram a proteína fluorescente verde e outros marcadores para estudar a interação, in vivo e in situ, entre Trichoderma spp. e o fungo patogênico ou a planta.

Em plantas infectadas por microrganismos potencialmente patogênicos, há primeiro a acumulação de proteínas induzidas patogenicamente, ou proteínas-PR (Hartleb et al., 1997). Após a penetração do patógeno, há formação de um ou mais tipos de estruturas, que apresentam maior ou menor sucesso na defesa da planta, e podem apresentar poderosa atividade antifúngica (Hartleb et al., 1997; Karban \& Kuc, 1999; Xiuyun \& Tzi, 2005).

Exemplos bem caracterizados de proteínas-PR relacionadas à patogenicidade incluem as enzimas hidrolíticas beta-1,3-glucanase (E.C 3.2.1.59) e quitinase (E.C 3.2.1.14), induzidas por patógenos ou produtos químicos exógenos (Chet, 1993; Kim \& Hwang, 1994). Essas enzimas, que têm recebido progressiva atenção como importantes componentes do arsenal de proteínas de defesa das plantas, catalisam a hidrólise dos principais carboidratos da parede celular dos fungos: quitina e beta-1,3-glucano. Após a infecção, pode ocorrer um pronunciado aumento da atividade dessas enzimas (Chet, 1993; Agrios, 1997), que inibe o crescimento dos fungos (Hartleb et al., 1997) e libera oligossacarídeos elicitores que induzem a produção de fitoalexinas pelas plantas (Keen \& Yoshikawa, 1983; Hartleb et al., 1997). Entre os elicitores exógenos, o mais ativo é procedente da degradação de um beta-glucano da parede celular do fungo, pela ação da beta-glucanase (Sharp et al., 1984).
O ácido salicílico tem papel central como sinalizador, envolvido na defesa das plantas contra $\mathrm{o}$ ataque de microrganismos (Mauch et al., 1988). Aplicações exógenas de ácido salicílico, que induziram efetivamente a expressão gênica de proteínas envolvidas na indução da resistência sistêmica adquirida, levaram à investigação do papel do ácido salicílico endógeno na resistência a doenças (Chet, 1993). Sabe-se que o ácido salicílico promove a resistência sistêmica adquirida (SAR) e a acumulação de proteínas-PR em muitas espécies de plantas (Kessmann et al., 1994). Tratamento com conídios de $C$. lindemuthianum também pode ter esse efeito em feijoeiro (Dann \& Deverall, 1995).

O objetivo deste trabalho foi avaliar o potencial de proteção e a capacidade do fungo da raça delta de Colletotrichum lindemuthianum, em expressão de avirulência, de induzir a síntese das enzimas hidrolíticas quitinase e beta-1,3-glucanase em feijoeiro-comum, em dois estádios de desenvolvimento das plantas.

\section{Material e Métodos}

O trabalho foi conduzido na Embrapa Clima Temperado, em casa de vegetação, à temperatura de $25 \pm 2^{\circ} \mathrm{C}$ e umidade relativa de $79 \pm 5 \%$, com 14 horas de fotoperíodo e iluminação mista de $195 \mu \mathrm{E} \mathrm{s}^{-1} \mathrm{~m}^{-2}$. Foram utilizadas as cultivares de feijoeiro (Phaseolus vulgaris L.): $\mathrm{AB} 136$, padrão resistente a $C$. lindemuthianum; Carioca, padrão suscetível; Macanudo e Rio Tibagi. Foram avaliados dois estádios de desenvolvimento, em dois experimentos distintos.

No primeiro experimento, as sementes foram semeadas em bandejas de plástico $(55 \times 40 \times 15 \mathrm{~cm}) \mathrm{com}$ areia esterilizada, e irrigadas com solução nutritiva completa (Smith et al., 1963). As sementes germinaram e as plantas cresceram até atingir o estádio de plântulas com folhas primárias totalmente expandidas (V2).

No segundo experimento, as sementes foram semeadas em uma mistura esterilizada de solo, esterco e vermiculita $(5: 3: 1 \mathrm{v} / \mathrm{v} / \mathrm{v})$, em sacos de $3 \mathrm{~kg}$. As sementes germinaram e as plantas cresceram até o estádio de início de floração (R6).

Foi feita a aspersão de suspensão de Colletotrichum lindemuthianum raça delta avirulento, deácido salicílico $0,01 \mathrm{M}$ (indutor de referência) ou de água (testemunha) nas folhas, com atomizador manual. Após três dias da aplicação dos tratamentos, foram avaliadas as atividades das enzimas beta-1,3-glucanase e quitinase 
nas plantas. As plantas receberam, então, aspersão de suspensão do patótipo virulento proveniente do isolado 33/95 de C. lindemuthianum, e cinco dias depois foi reavaliada a atividade das enzimas.

$\mathrm{O}$ fungo avirulento da raça delta de C. lindemuthianum foi utilizado à concentração de $1,4 \times 10^{6}$ esporos por mililitro. O patótipo virulento (isolado 33/95 de C. Lindemuthianum) foi utilizado à concentração de $2,27 \times 10^{4}$ esporos por mililitro.

As suspensões de esporos foram obtidas a partir de colônias com dez dias de incubação, cultivadas em vagens de feijão. As vagens foram colocadas em tubos de ensaio com meio de cultura (Mathur et al., 1950). Os tubos foram autoclavados a $125^{\circ} \mathrm{C}$ por $15 \mathrm{~min}$ e resfriados por 3 a 4 horas. Após esse período, foi feita a repicagem dos fungos para os tubos, que foram, em seguida, incubados em BOD por dez dias, a $24^{\circ} \mathrm{C}$. Após o crescimento das colônias, foi preparada a suspensão de esporos. Em cada tubo, foi adicionado $0,5 \mathrm{~mL} \mathrm{~L}^{-1}$ de espalhante adesivo (tween $80 \%$ ) e $10 \mathrm{~mL}$ de água destilada. Os tubos foram agitados e a suspensão filtrada. Avaliou-se a concentração de esporos na suspensão e, então, a diluição com água destilada foi preparada para a realização dos tratamentos.

Após a aplicação dos tratamentos, as plantas foram mantidas em condições consideradas ideais para o crescimento do fungo: temperatura de $22 \pm 2^{\circ} \mathrm{C}$ e umidade relativa de $95 \%$, com iluminação mista de aproximadamente $195 \mu \mathrm{E} \mathrm{s}^{-1} \mathrm{~m}^{-2}$, por 14 horas.

As avaliações da severidade da doença, realizadas 5 dias após tratamento com $C$. lindemuthianum virulento, foram feitas de acordo com a escala descritiva para antracnose (Rava et al., 1993), tendose considerado a presença de infecção em folhas, caules e ramos, que variou entre o grau 1 (plantas sem sintomas) e o grau 9 (infecção muito severa). Os dados relativos à infecção foram transformados em índice de severidade da doença, pela fórmula de Mckinney (Embrapa, 1976).

$\mathrm{O}$ delineamento experimental foi o inteiramente casualizado, em esquema fatorial, com parcelas subdivididas, e 5 repetições. Foram dispostas nas parcelas as quatro cultivares $\mathrm{x}$ três tratamentos $\mathrm{e}$, nas subparcelas, os estádios de desenvolvimento das plantas.

Para a determinação da atividade das enzimas beta-1,3-glucanase e quitinase, foram coletados o terceiro par de folhas das plantas, no estádio R6, e o segundo par de folhas, no estádio V2, três dias após a aplicação dos tratamentos e cinco dias após a aplicação do isolado virulento de C. lindemuthianum. Discos de $0,5 \mathrm{~cm}$ de diâmetro, retirados entre as nervuras, foram pesados, rapidamente congelados em gelo seco e armazenados a $-80^{\circ} \mathrm{C}$ para análises posteriores.

A beta-1,3-glucanase foi determinada colorimetricamente, pelo método de Abeles \& Forrence (1970), com modificações, tendo-se utilizado laminarina e dinitrossalicilato como substratos.

As folhas congeladas foram homogeneizadas à temperatura de $2^{\circ} \mathrm{C}$, em tampão citrato de sódio $0,1 \mathrm{M}$ (pH 5,4), com 0,1\% (v/v) de beta-mercaptoetanol e $0,1 \%$ $(\mathrm{p} / \mathrm{v})$ de L-ácido ascórbico. A presença desses agentes redutores, no tampão de extração, é essencial para se obter alta atividade da beta-1,3-glucanase. O homogeneizado foi centrifugado a $15.000 \mathrm{~g}$ por $30 \mathrm{~min} \mathrm{a} 4^{\circ} \mathrm{C}$, e o sedimento foi descartado. O sobrenadante - extrato bruto - foi tratado com igual volume de acetona gelada a $-20^{\circ} \mathrm{C}$ por $30 \mathrm{~min}$, e a suspensão foi centrifugada a $13.000 \mathrm{~g}$ por $10 \mathrm{~min}$ a $4^{\circ} \mathrm{C}$. Os precipitados sedimentados foram secos a vácuo, por 24 horas, em temperatura ambiente, e foram ressuspensos em $62,5 \mu \mathrm{L}$ de tampão acetato de sódio $0,05 \mathrm{M}$ (pH 5,2). A essa suspensão, foi adicionado $0,1 \mathrm{~mL}$ de laminarina a $4 \%$, e a mistura foi incubada a $40^{\circ} \mathrm{C}$ por $10 \mathrm{~min}$. A reação foi interrompida pela adição de $375 \mu \mathrm{L}$ do reagente dinitrossalicilato à mistura, seguida de aquecimento em banho de água fervente por $5 \mathrm{~min}$. A solução corada resultante foi diluída com $4,5 \mathrm{~mL}$ de água e agitada em vortex. As leituras das absorvâncias foram realizadas a $500 \mathrm{~nm}$, em espectrofotômetro UV PC Shimadzu.

A unidade de atividade da enzima foi definida como a quantidade de enzima que produziu o equivalente a $1 \mathrm{nmol}$ de glicose por $1.000 \mathrm{~mL}$ de preparação por miligrama de proteína, nas condições descritas acima.

A atividade da quitinase foi avaliada no mesmo extrato bruto preparado para a determinação da atividade da beta-1,3-glucanase. Quitina coloidal (Sigma Chemical), na concentração $10 \mathrm{mg} \mathrm{mL}^{-1}$, foi preparada de acordo com procedimentos descritos por Dann \& Deverall (1995) e Shimahara \& Takiguchi (1998) e usada como substrato da enzima.

A atividade foi calculada como miliunidades por miligrama de proteína no extrato, em que 1 miliunidade é igual a $1 \mathrm{nmol}$ de $\mathrm{N}$-acetil-D-glicosamina por min, liberado por $1.000 \mathrm{~mL}$ de preparação, a partir dos oligossacarídeos. 
A concentração de proteína foi avaliada pelo método de Lowry (Lowry et al., 1951).

As análises de variância e os cálculos do coeficiente de correlação foram feitos segundo os métodos de Zonta \& Machado (1984). Para comparação das médias, foi empregado o teste de Duncan, a 5\% de probabilidade.

\section{Resultados e Discussão}

Observou-se interação entre os tratamentos e as atividades enzimáticas, em V2 e R6. As atividades da quitinase (Tabela 1) e da beta-1,3-glucanase (Tabela 2) aumentaram significativamente pela aplicação dos tratamentos e inoculação do patótipo virulento de C. lindemuthianum na cultivar $\mathrm{AB} 136$, com menor aumento nas cultivares Macanudo, Rio Tibagi e Carioca. A cultivar AB 136, de ampla resistência à antracnose, não desenvolveu nenhum tipo de sintoma da doença, no tratamento com o patótipo virulento (33/95) de C. lindemuthianum. A cultivar Carioca apresentou alta suscetibilidade ao patótipo virulento e nenhuma à raça delta de $C$. lindemuthianum. As correlações entre a atividade da quitinase $(p>0,997)$ e da beta-1,3-glucanase $(p>0,995)$ com a severidade da antracnose foram negativas e altamente significativas.

Com a aplicação dos tratamentos no estádio R6 (Tabela 1), não houve diferença estatística significativa na atividade da quitinase, aos três dias após a inoculação, na cultivar Rio Tibagi, entre os tratamentos de indução com o fungo avirulento $\mathrm{e}$ com o ácido salicílico. Também não houve diferença significativa entre esses tratamentos aos cinco dias após a inoculação do patótipo virulento. Essa cultivar apresentou rápida resposta da quitinase ao ataque do patótipo virulento, o que resultou em menor índice de severidade da doença nesse tratamento, quando comparado ao índice de severidade em plantas que não receberam indução.

A maior atividade da quitinase e da beta1,3-glucanase na cultivar AB136, após indução ou reação ao patótipo virulento, pode ter ocorrido em razão da rapidez de acúmulo das enzimas nessa cultivar, que é resistente ao C. lindemuthianum, o que não aconteceu na cultivar Carioca, considerada suscetível. A explicação para esse fato, de acordo com Karban \& Kuc (1999), é que o aumento da atividade das enzimas relacionadas à patogenicidade depende do desencadeamento rápido da síntese "de novo", ativada por elicitores provenientes das reações de defesa da planta contra o fungo. Lawrence et al. (2000) também verificaram que genótipos de tomate resistentes à Alternaria solani apresentaram um acúmulo mais rápido de isoenzimas de quitinase e beta-1,3-glucanase do que os genótipos suscetíveis.

Os resultados referentes à cultivar $\mathrm{AB} 136$ estão de acordo com os observados por Alzate-Marin et al. (1997), que recomendaram essa cultivar como doadora de marcadores moleculares, em programas de desenvolvimento de cultivares de feijoeiro-comum resistentes à antracnose, por ter sido resistente a 25 raças de $C$. lindemuthianum identificadas no Brasil.

Tabela 1. Atividade da quitinase, em plantas de feijoeiro nos estádios V2 e R6 das cultivares AB 136, Rio Tibagi, Carioca e Macanudo, após três dias da inoculação de C. lindemuthianum, e cinco dias após aplicação do patótipo virulento (33/95) de C. lindemuthianum ${ }^{(1)}$.

\begin{tabular}{|c|c|c|c|c|c|c|c|c|}
\hline \multirow[t]{2}{*}{ Tratamento } & \multicolumn{4}{|c|}{ Três dias após a inoculação } & \multicolumn{4}{|c|}{ Cinco dias após a aplicação do patótipo virulento } \\
\hline & AB 136 & Rio Tibagi & Carioca & Macanudo & AB 136 & Rio Tibagi & Carioca & Macanudo \\
\hline & \multicolumn{8}{|c|}{ Estádio V2 } \\
\hline $\begin{array}{l}\text { Testemunha (plantas sem } \\
\text { inóculo) }\end{array}$ & $88,00 \mathrm{cA}$ & $57,33 \mathrm{cA}$ & $37,66 \mathrm{cA}$ & $59,66 \mathrm{cA}$ & $100,33 \mathrm{bA}$ & $70,33 \mathrm{dA}$ & $71,00 \mathrm{cA}$ & $72,33 \mathrm{dA}$ \\
\hline C. lindemuthianum (raça delta) & $742,60 \mathrm{bB}$ & $509,00 \mathrm{bB}$ & $300,00 \mathrm{bB}$ & $548,33 \mathrm{bB}$ & $859,00 \mathrm{aA}$ & $558,00 \mathrm{bA}$ & $209,00 \mathrm{bA}$ & $606,00 \mathrm{bA}$ \\
\hline Água & $89,00 \mathrm{cB}$ & $57,33 \mathrm{cB}$ & $37,60 \mathrm{cB}$ & $59,66 \mathrm{cB}$ & $871,00 \mathrm{aA}$ & $380,00 \mathrm{cA}$ & $97,33 \mathrm{cA}$ & $406,30 \mathrm{cA}$ \\
\hline \multirow[t]{2}{*}{ Ácido salicílico } & $796,00 \mathrm{aB}$ & $541,30 \mathrm{aA}$ & $310,00 \mathrm{aA}$ & $558,66 \mathrm{aB}$ & $864,00 \mathrm{aA}$ & $588,00 \mathrm{aA}$ & $239,00 \mathrm{aB}$ & $620,00 \mathrm{aA}$ \\
\hline & \multicolumn{8}{|c|}{ Estádio R6 } \\
\hline $\begin{array}{l}\text { Testemunha (plantas sem } \\
\text { inóculo) }\end{array}$ & $90,00 \mathrm{cA}$ & $62,83 \mathrm{bA}$ & $42,00 \mathrm{cA}$ & $69,26 \mathrm{cA}$ & $100,00 \mathrm{dA}$ & $64,83 \mathrm{cA}$ & $69,00 \mathrm{dA}$ & $79,33 \mathrm{dA}$ \\
\hline C. lindemuthianum (raça delta) & $755,33 \mathrm{bB}$ & $620,53 \mathrm{aB}$ & $301,90 \mathrm{bA}$ & $594,33 \mathrm{bB}$ & $897,00 \mathrm{bA}$ & $660,00 \mathrm{aA}$ & $257,00 \mathrm{cB}$ & $673,50 \mathrm{bA}$ \\
\hline Água & $91,10 \mathrm{cB}$ & $63,83 \mathrm{bB}$ & $42,73 \mathrm{cB}$ & $71,13 \mathrm{cB}$ & $796,66 \mathrm{cA}$ & $571,00 \mathrm{bA}$ & $304,67 \mathrm{bA}$ & $598,00 \mathrm{cA}$ \\
\hline Ácido salicílico & $836,66 \mathrm{aB}$ & $630,00 \mathrm{aB}$ & $399,00 \mathrm{aA}$ & $632,00 \mathrm{aB}$ & $971,66 \mathrm{aA}$ & $663,33 \mathrm{aA}$ & $334,33 \mathrm{aB}$ & $752,33 \mathrm{aA}$ \\
\hline
\end{tabular}


Balardin et al. (1997) também recomendaram essa cultivar como uma das fontes de genes de resistência ao C. lindemuthianum, por conferir maior durabilidade da resistência. Alta variabilidade patogênica do C. lindemuthianum tem sido detectada em muitas áreas da América Latina (Sicard et al.,1997; Souza et al., 2007), e a indução da resistência das plantas é uma forma de garantir que a resistência não seja quebrada por um período maior de tempo.

Também foi observada interação dos tratamentos na redução da severidade da doença. O índice de severidade da doença diminuiu com a aplicação dos tratamentos, em todas as cultivares utilizadas, inclusive a Carioca (Tabela 3).

O aumento da atividade das enzimas avaliadas neste trabalho contribui para a resistência do feijoeiro ao C. lindemuthianum, pela ação hidrolítica sobre betaglucanos e quitina presentes na parede celular de muitos fungos (Chet, 1993; Djonovic et al., 2007). $\mathrm{O}$ envolvimento dessas enzimas na defesa ativa das plantas contra patógenos está apoiado em trabalhos que demonstraram, in vitro, que elas inibem o crescimento de microrganismos (Schlumbaum et al., 1986; Mauch et al., 1988; Xiuyun \& Tzi, 2005). A maior indução de resistência sistêmica, com a maior atividade da beta-1,3-glucanase ou da quitinase após tratamentos com C. lindemuthianum e ácido salicílico, evidenciada pela redução da severidade em todas as cultivares avaliadas, é consistente com os resultados obtidos por Dann \& Deverall (1995) e por Costa et al. (2000).

As plantas no estádio R6 apresentaram acréscimo acentuado na atividade da beta-1,3-glucanase, após a indução (Tabela 2), porém, apresentaram decréscimo na atividade enzimática após os tratamentos com o patótipo virulento. Esse fato indica que pode ter havido desgaste energético maior da planta nesse estádio de desenvolvimento, pois a floração, por si só, demanda maior atividade metabólica. Esse resultado indica que o melhor estádio para os tratamentos de indução da resistência é, provavelmente, o de plântula (V2).

Nas plantas das cultivares Macanudo e Rio Tibagi, no estádio R6, a atividade da quitinase foi maior após a inoculação do patótipo virulento, o que não aconteceu na cultivar Carioca (Tabela 1). No entanto, na cultivar Macanudo, após tratamento com AS, esse efeito foi mais acentuado e pode ter-se refletido no índice de severidade da doença significativamente menor $(0,31)$ do que o observado na Rio Tibagi $(0,38)$ (Tabela 3). Esses dados podem ser resultantes da maior ação hidrolítica da quitinase sobre os componentes da parede celular das hifas, uma vez que a cultivar Macanudo apresentou alta atividade desta enzima $752,33 \mathrm{nmol} \mathrm{mg}^{-1}$. Esses resultados são condizentes com os obtidos por Benhamou et al. (1993), que constataram, por meio de marcador citoquímico de quitina, alterações nas hifas de Rhizoctonia solani, pela ação da quitinase $35 \mathrm{~S}$ de feijão em canola transgênica, que esteve correlacionada à degradação de quitina extensiva. Trabalhos de Djonovic et al. (2007) e Massart \& Jijakli (2007) indicam que as enzimas hidrolíticas, tanto ativadas por genes que as codificam quanto por agentes de biocontrole, podem ser utilizadas com sucesso para se realizar melhor controle de fungos.

Tabela 2. Atividade da beta-1,3-glucanase, em plantas de feijão nos estádios V2 e R6, das cultivares AB 136, Rio Tibagi, Carioca e Macanudo, após três dias da inoculação de $C$. lindemuthianum, e cinco dias após aplicação do patótipo virulento $(33 / 95)$ de C. lindemuthianum ${ }^{(1)}$.

\begin{tabular}{|c|c|c|c|c|c|c|c|c|}
\hline \multirow[t]{2}{*}{ Tratamento } & \multicolumn{4}{|c|}{ Três dias após a inoculação } & \multicolumn{4}{|c|}{ Cinco dias após a aplicação do patótipo virulento } \\
\hline & $\mathrm{AB} 136$ & Rio Tibagi & Carioca & Macanudo & AB 136 & Rio Tibagi & Carioca & Macanudo \\
\hline & \multicolumn{8}{|c|}{ Estádio V2 } \\
\hline Testemunha (plantas sem inóculo) & $1,78 \mathrm{cA}$ & $1,40 \mathrm{bA}$ & $1,29 \mathrm{bA}$ & $1,30 \mathrm{bA}$ & $4,07 \mathrm{cA}$ & $1,60 \mathrm{cA}$ & $1,57 \mathrm{cA}$ & $1,90 \mathrm{dA}$ \\
\hline C. lindemuthianum (raça delta) & $27,90 \mathrm{bB}$ & $17,66 \mathrm{aB}$ & $13,06 \mathrm{aB}$ & $24,16 \mathrm{aA}$ & $38,26 \mathrm{bA}$ & $25,56 \mathrm{aA}$ & $18,73 \mathrm{aA}$ & $24,16 \mathrm{bA}$ \\
\hline Água & $1,78 \mathrm{cB}$ & $1,43 \mathrm{bB}$ & $1,32 \mathrm{bB}$ & $1,32 \mathrm{bB}$ & $36,00 \mathrm{bA}$ & $13,00 \mathrm{bA}$ & $9,00 \mathrm{bA}$ & $16,00 \mathrm{cA}$ \\
\hline \multirow[t]{2}{*}{ Ácido salicílico } & $31,00 \mathrm{aB}$ & $18,99 \mathrm{aB}$ & $14,66 \mathrm{aA}$ & $20,10 \mathrm{aB}$ & $40,10 \mathrm{aA}$ & $29,99 \mathrm{aA}$ & $15,02 \mathrm{aA}$ & $30,83 \mathrm{aA}$ \\
\hline & \multicolumn{8}{|c|}{ Estádio R6 } \\
\hline Testemunha (plantas sem inóculo) & $5,20 \mathrm{cA}$ & $3,82 \mathrm{cA}$ & $2,72 \mathrm{bA}$ & $3,93 \mathrm{cA}$ & $6,26 \mathrm{cA}$ & $5,10 \mathrm{cA}$ & $4,20 \mathrm{cA}$ & $5,30 \mathrm{cA}$ \\
\hline C. lindemuthianum (raça delta) & $41,33 \mathrm{bA}$ & $22,00 \mathrm{bA}$ & $16,33 \mathrm{aA}$ & $25,50 \mathrm{bA}$ & $36,00 \mathrm{bB}$ & $18,63 \mathrm{bB}$ & $13,23 \mathrm{bB}$ & $25,50 \mathrm{aA}$ \\
\hline Água & $5,26 \mathrm{cB}$ & $3,85 \mathrm{cB}$ & $2,85 \mathrm{bB}$ & $3,96 \mathrm{cB}$ & $45,33 \mathrm{aA}$ & $14,00 \mathrm{bA}$ & $12,50 \mathrm{bA}$ & $18,00 \mathrm{bA}$ \\
\hline Ácido salicílico & $53,66 \mathrm{aA}$ & $30,33 \mathrm{aA}$ & $17,90 \mathrm{aA}$ & $33,60 \mathrm{aA}$ & $39,00 \mathrm{bB}$ & $24,26 \mathrm{aB}$ & $14,53 \mathrm{aB}$ & $26,60 \mathrm{aB}$ \\
\hline
\end{tabular}


Tabela 3. Índice de Mckinney, relativo à severidade da infecção por Colletotrichum lindemuthianum (patótipo virulento), nas cultivares AB 136, Rio Tibagi, Carioca e Macanudo, nos estádios de plântula (V2) e de início de floração (R6), após tratamentos com ácido salicílico (AS) e C. lindemuthianum raça delta (fungo avirulento).

\begin{tabular}{|c|c|c|c|c|c|c|c|c|}
\hline \multirow[t]{2}{*}{ Tratamento } & \multicolumn{2}{|c|}{ AB 136} & \multicolumn{2}{|c|}{ Rio Tibagi } & \multicolumn{2}{|c|}{ Macanudo } & \multicolumn{2}{|c|}{ Carioca } \\
\hline & V2 & R6 & $\mathrm{V} 2$ & R6 & $\mathrm{V} 2$ & R6 & $\mathrm{V} 2$ & R6 \\
\hline Plantas sadias sem inóculo & 0,1 & 0,1 & $0,10 \mathrm{~d}$ & $0,10 \mathrm{~d}$ & $0,10 \mathrm{~d}$ & $0,10 \mathrm{~d}$ & $0,10 \mathrm{~d}$ & $0,10 \mathrm{~d}$ \\
\hline Água & 0,1 & 0,1 & $0,76 \mathrm{a}$ & $0,70 \mathrm{a}$ & $0,70 \mathrm{a}$ & $0,68 \mathrm{a}$ & $0,96 \mathrm{a}$ & $0,87 \mathrm{a}$ \\
\hline C. lindemuthianum (raça delta) & 0,1 & 0,1 & $0,43 b$ & $0,41 b$ & $0,45 b$ & $0,48 b$ & $0,76 b$ & $0,66 \mathrm{a}$ \\
\hline AS & 0,1 & 0,1 & $0,30 \mathrm{c}$ & $0,38 \mathrm{c}$ & $0,30 \mathrm{c}$ & $0,31 \mathrm{c}$ & $0,61 \mathrm{c}$ & $0,61 \mathrm{a}$ \\
\hline $\mathrm{CV}(\%)$ & - & - & 1,5 & 2,0 & 2,7 & 2,0 & 1,0 & 3,0 \\
\hline
\end{tabular}

${ }^{(1)}$ Médias seguidas por letras iguais, nas colunas, não diferem entre si pelo teste de Duncan, a $5 \%$ de probabilidade.

A aplicação de ácido salicílico e a inoculação de fungo avirulento de $C$. lindemuthianum foram igualmente eficientes em induzir maior atividade da beta-1,3-glucanase e quitinase no estádio V2 de desenvolvimento das plantas (Tabela 2), que apresentaram índice de severidade da doença menor nesses tratamentos (Tabela 3), como resultado de maior indução do sistema de defesa das plantas. No estádio R6, o tratamento com ácido salicílico foi mais eficiente em reduzir o índice de severidade da antracnose.

O biocontrole da antracnose já foi relatado com sucesso por Rahe et al. (1969), em estudo com a cultivar Perry Marrow. Esses autores aplicaram nas folhas um inóculo de raça avirulenta e, 48 horas depois, aplicaram um inóculo de raça virulenta. Observaram, então, que as plantas foram totalmente protegidas contra a raça virulenta e, também, que quando ocorria indução à resistência, o genótipo apresentava rápida resposta de hipersensibilidade, caracterizada pela presença de numerosas pintas marrom-avermelhadas, distribuídas sobre as hastes das plântulas.

A eficiência do fungo avirulento $C$. lindemuthianum raça delta em induzir a resistência sistêmica em plantas de feijão foi comprovada pela ativação de outras enzimas, além das hidrolíticas, conforme constataram Campos et al. (2003), em estudo relacionado à proteção das plantas e atividade da fenilalanina amônia-liase e da chalcona sintase, e Campos et al. (2004), que constataram a ativação de uma isoenzima do grupo peroxidase.

\section{Conclusões}

1. A severidade da doença é drasticamente reduzida com a utilização do fungo Colletotrichum lindemuthianum raça delta, em expressão de avirulência.
2. O fungo Colletotrichum lindemuthianum raça delta tem potencial para o biocontrole da antracnose feijoeiro.

\section{Agradecimentos}

À Fundação de Amparo à Pesquisa do Estado do Rio Grande do Sul, pelo financiamento parcial das pesquisas.

\section{Referências}

ABELES, F.B.; FORRENCE, L.E. Temporal and hormonal control of beta-1,3-glucanase in Phaseolus vulgaris L. Plant Physiology, v.45, p.395-400, 1970.

AGRIOS, G.N. Plant pathology. $4^{\text {th }}$ ed. San Diego: Academic Press, 1997. 635p.

ALABOUVETTE, C.; OLIVAIN, C.; STEINBERG, C. Biological control of plant diseases: the European situation. European Journal of Plant Pathology, v.114, p.329-341, 2006.

ALZATE-MARIN, A.L.; BAIA, G.S.; PAULA-JÚNIOR, T.J. de; CARVALHO, G.A de; BARROS, E.G. de; MOREIRA, M.A. A inheritance of anthracnose resistance in common bean differential cultivar AB 136. Plant Disease, v.81, p.996-998, 1997.

BALARDIN, R.S.; JAROSZ, M.; KELLY, J.D. Virulence and molecular diversity in Colletotrichum lindemuthianum from South, Central, and North America. Phytopathology, v.87, p.1184-1191, 1997.

BENHAMOU, N.; BROGLIE, K.; CHET, I.; BROGLIE, R. Cytology of infection of 35S-bean chitinase transgenic canola plants by Rhizoctonia solani, cytochemical aspects of chitin breakdown in vivo. The Plant Journal, v.4, p.295-305, 1993.

CAMPOS, A.D.; FERREIRA, A.G.; HAMPE, M.M.V.; ANTUNES, I.F.; BRANCÃO, N.; SILVEIRA, E.P.; OSÓRIO, V.A.; AUGUSTIN, E. Atividade de peroxidase e polifenoloxidase na resistência do feijão à antracnose. Pesquisa Agropecuária Brasileira, v.39, p.637-643, 2004.

CAMPOS, A.D.; FERREIRA, A.G.; HAMPE, M.M.V.; ANTUNES, I.F.; BRANCÃO, N.; SILVEIRA, E.P.; SILVA, J.B.; OSÓRIO, V.A. Induction of chalcone synthase and phenylalanine ammonia-lyase by salicylic acid and Colletotrichum lindemuthianum in common bean. Brazilian Journal of Plant Physiology, v.15, p.129-134, 2003. 
CHET, I. Biotechnology in plant disease control. New York: Wiley-Liss, 1993. 373p.

COSTA, H.S.; RIOS-RUIZ, W.F.; LAMBAIS, M.R. Ácido salicílico inibe a formação de micorrizas arbusculares e modifica a expressão de quitinases e beta-1,3-glucanases em raízes de feijoeiro. Scientia Agricola, v.57, p.19-25, 2000.

DANN, E.K.; DEVERALL, B.J. Effectiveness of systemic resistance in bean against foliar and soilborne pathogens as induced by biological and chemical means. Plant Pathology, v.44, p.458-466, 1995.

DJONOVIC, S.; VITTONE, G.; MENDOZA-HERRERA, A.; KENERLEY, C.M. Enhanced biocontrol activity of Trichoderma virens transformants constitutively coexpressing beta-1,3- and beta1,6-glucanase genes. Molecular Plant Pathology, v.8, p.469-480, 2007.

EMBRAPA. Centro Nacional de Pesquisa de Arroz e Feijão. Manual de métodos de pesquisa em feijão: primeira aproximação. Goiânia, 1976. 81p.

HARTLEB, H.; HEITEFUSS, R.; HOPPE, H. Resistance of crop plants against fungi. Germany: Fischer, 1997. 544p.

JANISIEWICZ, W.; KORSTEN, L. Biological control of postharvest diseases of fruits. Annual Review of Phytopathology, v.40, p.411-441, 2002.

KARBAN, R.; KUC, J. Induced resistance against pathogens and herbivores: an overview. In: AGRAWAL, A.A.; TUZUN, S.; BENT, E. (Ed.). Induced plant defenses against pathogens and herbivores: biochemistry, ecology and agriculture. St. Paul: APS Press, 1999. p.1-16.

KEEN, N.T.; YOSHIKAWA, M. $\beta$-1,3-endoglucanase from soybean releases elicitor - active carbohydrates from fungus cell walls. Plant Physiology, v.71, p.460-465, 1983.

KESSMANN, H.; STAUB, T.; HOFMANN, C.; MAETZKE, T.; HERZOG, J.; WARD, E.; UKNES, S.; RYALS, J. Induction of systemic - acquired disease resistance in plants by chemicals. Annual Review of Phytopathology, v.32, p.439-459, 1994.

KIM, Y.J.; HWANG, B.K. Differential accumulation of beta1,3-glucanase and chitinase isoforms in pepper stems infected by compatible and incompatible isolates of Phytophthora capsici. Plant Physiology, v.45, p.195-209, 1994.

LAWRENCE, C.B.; SINGH, N.P.; QIU, J.; GARDNER, R.G.; TUZUN, S. Constitutive hydrolytic enzymes are associated with polygenic resistance of tomato to Alternaria solani and may function as an elicitor release mechanism. Physiological and Molecular Plant Pathology, v.57, p.211-220, 2000.

LOWRY, O.H.; ROSEBROUGH, N.J.; FARR, A.L.; RANDALL, R.J. Protein measurement with the folin-phenol reagent. Journal of Biological Chemistry, v.193, p.193-265, 1951.

MASSART, S.; JIJAKLI, H. Use of molecular techniques to elucidate the mechanisms of action of fungal biocontrol agents: a review. Journal of Microbiological Methods, v.69, p.229-241, 2007.
MATHUR, R.S.; BARNETT, H.L.; LILLY, V.G. Sporulation of Colletotrichum lindemuthianum in culture. Phytopathology, v.40, p.104-114, 1950.

MAUCH, F.; MAUCH-MANI, B.; BOLLER, T. Antifungal hydrolases in pea tissue. II. Inhibition of fungal growth by combinations of chitinase and beta-1,3-glucanase. Plant Physiology, v.88, p.936-942, 1988.

MONTESINOS, E. Development, registration and commercialization of microbial pesticides for plant protection. International Microbiology, v.6, p.245-252, 2003.

RAHE, J.E.; KUC, J.; CHUANG, C.M.; WILLIANS, E.B. Induced resistance in Phaseolus vulgaris to bean anthracnose. Phytopathology, v.59, p.1641-1645, 1969.

RAVA, C.A.; MOLINA, J.; KAUFFMANN, M.; BRIONES, I. Determinación de razas fisiológicas de Colletotricum lindemuthianum en Nicarágua. Fitopatologia Brasileira, v.18, p.388-391, 1993.

SCHLUMBAUM, A.; MAUCH, F.; VOGELI, U.; BOLLER, T. Plant chitinases are potent inhibitors of fungal growth. Nature, v.324, p.365-367, 1986.

SHARP, J.K.; VALENTE, B.; ALBERSHEIM, P. Purification and partial characterization of a beta-glucan fragment that elicits phytoalexin accumulation in soybean. Journal of Biological Chemistry, v.259, p.11312-11320, 1984.

SHIMAHARA, Y.; TAKIGUCHI, Y. Preparation of crustacean chitin. In: ABELSON, J.N.; SIMON, M.I. (Ed). Methods in Enzymology. California: Academic Press, 1998. 423p.

SICARD, D.; BUCHET, S.; MICHALAKIS, Y.; NEEMA, C. Genetic variability of Colletotrichum lindemuthianum in wild populations of common bean. Plant Pathology, v.46, p.355-365, 1997.

SMITH, C.A.; BAILEY, C.H.; HOUGH, L.F. Methods for germinating seeds of some fruit species with special reference to growing seedlings from immature embryos. New Brunswick: The State University of New Jersey, 1963. 62p.

SOUZA, B.O. de; SOUZA, E.A. de; MENDES-COSTA, M.A. Determinação da variabilidade em isolados de Colletotrichum lindemuthianum por meio de marcadores morfológicos e culturais. Ciência e Agrotecnologia, v.31, p.1007-1013, 2007.

WOO, S.L.; SCALA, F.; RUOCCO, M.; LORITO, M. The molecular biology of the interactions between Trichoderma spp., phytopathogenic fungi, and plants. Phytopathology, v.96, p.181-185, 2006.

XIUYUN, Y.; TZI, B.N. A chitinase with antifungal activity from the mung bean. Protein Expression and Purification, v.40, p.230-236, 2005 .

ZONTA, E.P.; MACHADO, A.A. Sistema de análise estatística para microcomputadores. Pelotas: Ufpel, 1984. 48p. 